\title{
La voluntad libre en Hegel
}

\author{
Free volition in Hegel \\ JESÚS EZQUERRA GÓMEZ \\ Universidad de Zaragoza
}

Recibido: 26-05-2009 Aprobado definitivamente: 08-06-2009

RESUMEN

Este ensayo reexamina la concepción hegeliana de la voluntad libre tal como es expuesta, principalmente, en la introducción de los Fundamentos de la filosofía del derecho. Según Hegel la voluntad, en tanto que conciencia práctica, crea su objeto. Por eso puede reconocerse en él. Esa creación es la libertad. Lo que la voluntad libre quiere no es sino ella misma. Ser libre es, por lo tanto, quererse libre. En esta tesis alienta, a mi juicio, el carácter revolucionario del pensamiento político hegeliano.

\section{PALABRAS CLAVE \\ HEGEL, VOLUNTAD LIBRE, LIBERTAD, DERECHO, CONCIENCIA PRÁCTICA, AUTODETERMINACIÓN}

\begin{abstract}
This paper re-examines the Hegelian conception of free volition as it is put forward mainly in the introduction of Elements of the Philosophy of Right. According to Hegel the will, being practical conscience, creates its object. For that reason the will can be recognized in this object. This creation is freedom. So what the free will wants is the free will itself. To be free is, therefore, the will to be free. In my opinion this thesis shows the revolutionary character of Hegel's political thought.

KEYWORDS

HEGEL, FREE VOLITION, FREEDOM, RIGHT, PRACTICAL CONSCIENCE, SELFDETERMINATION
\end{abstract}


«LES HOMMES NAISSENT ET DEMEURENT LIBRES» dice el artículo primero de la Déclaration des droits de l'homme en soçiété de 1789. La libertad es el primero de los derechos conquistados por la revolución. Si la filosofía es «ihre Zeit in Gedanken erfasst» (el propio tiempo concebido en pensamientos), como afirma el prólogo a los Fundamentos de la filosofía del derecho, ${ }^{1}$ tarea primera y fundamental de la filosofía será «concebir en pensamientos» este primordial derecho. El tiempo de la libertad exige una filosofía de la libertad que dé cuenta plena de él, que sea su autoconciencia. La de Hegel pretende ser esa filosofía. En Hegel el derecho a la libertad está fundado en la libertad misma. Sólo el ejercicio efectivo de la libertad nos hace poseedores de tal derecho. Únicamente la libertad nos hace libres. Dicho de otro modo: la libertad es un derecho porque el derecho es ya la libertad. Eso es el derecho para Hegel: la libertad realizada.

\section{EL DERECHO ES LA LIBERTAD REALIZADA}

La idea del derecho. Ese es el objeto de la ciencia filosófica que tiene por objeto al derecho. ${ }^{2}$ Para Hegel la idea, como la girl en las películas de Buster Keaton, tiene una naturaleza poco etérea. No posee, paradójicamente, un carácter ideal: es más bien algo real. Por ejemplo, que la lógica termine y culmine con la idea significa que deja de ser lógica, es decir, ese «reino de sombras», como es denominada en la introducción a la versión de 1832 de la Doctrina del ser, ${ }^{3}$ y se hace realidad: espacio, tiempo, materia..., es decir, naturaleza. «La idea es -escribe Hegel- la unidad del concepto y la realidad» (die Idee die Einheit des Begriffs und der Realität ist).$^{4}$ La realidad no está duplicada en Hegel por una idealidad que salvaguarde su sentido último. La idea no es una noción abstracta, separada (en el sentido del choristós platónico) de lo ideado por ella; no es un «trasmundo» que rija como un télos el devenir natural o histórico, sino que es ese mismo devenir en tanto que requerido, exigido, por su concepto. La idea

1 Grundlinien der Philosophie des Rechts (citaré en adelante esta obra con la abreviatura: GPhR): G. W.F. Hegel, Werke, ed. de E. Moldenhauer y K.M. Michel, Frankfurt a. M.: Suhrkamp, 1986 (citaré en adelante esta edición con la abreviatura: Werke), t. VII, p. 26.

2 GPhR § 1: Werke VII, p. 29.

3 G. W. F. Hegel, Gesammelte Werke, ed. de la Rheinisch-Westfälischen Akademie der Wissenschaften en colaboración con la Deutsche Forschungsgemeinschaft, Hamburg: Felix Meiner, 1968 ss. (citaré en adelante esta edición con la abreviatura: $G W$ ), t. XXI, p. 42.

4 Wissenschat der Logik (citaré en adelante esta obra con la abreviatura: WdL) (1816): GW XII, p. 175. En una nota manuscrita de Hegel al $\S 28$ de la introducción a los Fundamentos de la Filosofía del Derecho leemos: «Der Geist will Idee sein-Begriff und Dasein» (El espíritu quiere ser idea - concepto y existencia): Werke VII, p. 79.. 
es lo verdaderamente real. Por decirlo en términos kojèvianos: El concepto es el tiempo. ${ }^{5}$

La idea del derecho, por lo tanto, será la unidad del concepto del derecho y de su realidad. Esta realidad no es algo adjetivo o accidental; no se trata de que el concepto adquiera realidad de un modo tal que, eventualmente, pudiera no haberlo hecho. La realidad del concepto viene dada por él mismo. El concepto (no los meros conceptos) -escribe Hegel- «es lo único que posee realidad efectiva pues se la da a sí mismo». ${ }^{6}$ "Realidad efectiva» traduce el vocablo «Wirklichkeit». Este designa en Hegel la unidad de lo interior y lo exterior, de la esencia y la existencia; es decir, lo que existe en virtud de su propia esencia. ${ }^{7}$ Por lo tanto, la afirmación de que el concepto se da a sí mismo la realidad efectiva se puede considerar el modo en el que Hegel reformula el argumento ontológico. El derecho en tanto que realización (Verwirklichung) del concepto es, por consiguiente, la existencia misma de Dios. Si tenemos en cuenta que para Hegel «lo libre es el concepto en su existencia» (das Freie ist der Begriff in seiner Existenz), ${ }^{8}$ podemos comprender la afirmación de que «La idea del derecho es la libertad» (Die Idee des Rechts ist die Freiheit). ${ }^{9}$

A la luz de lo que acabamos de decir no debe extrañarnos que Hegel caracterice el sistema del derecho como «el reino de la libertad hecha efectiva» (das Reich der verwirklichten Freiheit). ${ }^{10}$ La libertad hegeliana involucra su existencia, de modo análogo a como el Dios de la metafísica racionalista involucraba la suya. Esa existencia (Existenz) de la libertad son las leyes, las costumbres, las instituciones, et cetera. Dicho de otro modo: el derecho es positivo.

Hegel utiliza el adjetivo de raíz latina «positiv» (del latín «positus»,puesto). «Positivo» no tiene aquí el sentido que tenía en el joven Hegel (por ejemplo, en el texto de 1795-1796 titulado justamente La positividad de la religión cristiana). Allí significaba lo im-puesto por la autoridad al margen de la razón.

5 A. Kojève, Introduction à la lecture de Hegel, Paris: Gallimard, 1947, pp. 336 ss.

6 GPhR § 1 Anmerkung: Werke VII, p. 29. El subrayado es de Hegel.

7 En una anotación manuscrita de Hegel al primer parágrafo de los GPhR fechada el 30-X-1822, podemos leer: «Wirklichkeit ist nur die Einheit des Inneren und Äusseren - dass der Begriff nicht ein blosses Innere sei, sondern ebenso reales, - und das Äussere, Reale nicht eine begrifflose Realität, Dasein - Existenz, sondern sei wesentlich durch den Begriff bestimmt» (La realidad efectiva es únicamente la unidad de lo interior y lo exterior-que el concepto no sea un mero interior sino también real-y lo exterior, real no una realidad, ser ahí, existencia aconceptual, sino que esté esencialmente determinado por el concepto): Werke VII, p. 30.

8 WdL (1816): GW XII, p. 154.

9 Afirmación que, aunque se halla en el Zusatz, que, como es sabido es obra de E. Gans, el editor de los $G P h R$, es congruente con el texto de Hegel. Véase, por ejemplo, GPhR § 29: Werke VII, p. 80.

10 GPhR § 4: Werke VII, p. 46. 
Tampoco se opone a «negativo», sino que significa puesto. ${ }^{11}$ «Puesto» se dice en alemán «gesetz». Exactamente la misma palabra designa en alemán la ley. Con este adjetivo se alude al carácter objetivo que reviste aquí el Espíritu. Es decir, el derecho es objetivación o materialización (realización) del espíritu. Es, por así decir, el espíritu en tanto que puesto, es decir, en tanto que plasmado en costumbres, leyes, instituciones, et cetera.

Puesto se opone a dado. Lo dado es lo que acaece aleatoria, contingentemente; lo que está sin más ahí, porque sí. Lo puesto está también ahí, existe, pero necesariamente, exigido por la naturaleza o esencia de la cosa. Una montaña es algo dado, una pirámide, por el contrario, algo puesto. El derecho -escribe Hegel en el $\S 486$ de la Enciclopedia- es la «existencia de la voluntad libre» (Dasein des freien Willens). ${ }^{12}$ Por ser algo que existe (da ist), como las montañas, o las piedras, etc. lo denomina Hegel «una segunda naturaleza» (eine zweite Natur). ${ }^{13}$ Más aún: En el §146 de los Fundamentos de la Filosofía del Derecho (en la tercera parte: die Sittlichkeit) podemos leer que para el sujeto, el ser de la sustancia ética -sus leyes y fuerzas- constituye un poder «infinitamente más sólido que el ser de la naturaleza» $»^{14}$ : El sol, la luna, las montañas, los ríos, los objetos naturales, están dados; las costumbres, leyes e instituciones, por el contrario, están puestas.

Hegel no entiende, por lo tanto, el derecho (Recht) como una instancia rectificadora. El derecho no endereza tuertos, no corrige, a la manera de un tutor, el veleidoso y anárquico crecimiento de nuestra naturaleza. No limita o restringe la libertad entendida como arbitrio particular, como pretendieron Rousseau o Kant. ${ }^{15}$ Es justo al revés: el derecho, en tanto que existencia (Dasein) de la voluntad, es la condición de la libertad. No hay libertad sin derecho. La libertad o está realizada o no es libertad. Uno puede creerse libre pero sólo lo será efectivamente cuando realice su voluntad en relación con los otros en una comunidad. Las instituciones sociales y políticas, como el aire para la paloma kantiana, no sólo no son un impedimento, sino la condición de posibilidad de la libertad. Los Fundamentos de la filosofía del derecho son la exposición ${ }^{16}$ especulativa de la realización de la libertad. Como escribe P.-J. Labarrière,

11 Una anotación manuscrita de Hegel a este tercer parágrafo dice: «Positiv nicht dem Negativen entgegengesetzt, sondern positiv: es ist gesetzt, gilt» (positivo no se opone a lo negativo, sino que positivo es lo puesto, lo que vale): Werke VII, p. 42.

12 GW XX, p. 479.

$13 G P h R \S 4$, Werke VII, p. 46.

14 Werke VII, p. 295.

15 Véase la Anmerkung a GPhR § 29: Werke VII, pp. 80-81.

16 Sobre el sentido y alcance del concepto de «Darstellung» (exposición) en Hegel véase mi artículo: «La posición como exposición. Una aproximación a la Darstellung hegeliana», Pensamiento. Revista de investigación e información filosófica, Vol. 54, No 208 (1998), pp. 
Toda la filosofía de Hegel es una filosofía de la libertad; esta libertad no es real más que cuando permaneciendo en el mundo, ella lo «hace efectivo» según su sentido humano (identidad diferenciada de lo efectivo y lo racional), desplegandose en él como una «segunda naturaleza» en donde se da a conocer el universo del Espíritu; la «idea del Derecho», es justamente la inteligencia de ese encaminarse concreto gracias al cual la libertad se hace historia desplegándose en el universo de las estructuras, de las leyes y de las relaciones. ${ }^{17}$

\section{LA VOLUNTAD COMO CONCIENCIA PRÁCTICA}

La figura con la que culmina el espíritu subjetivo -por lo tanto el «el punto de partida» del derecho ${ }^{18}$ - es la voluntad libre (freie Wille). El derecho (el espíritu objetivo) no consistirá sino en la existencia (Dasein) de esa voluntad libre. ${ }^{19}$

¿«Voluntad libre»? Esta expresión es redundante, pues ¿qué es la voluntad sin libertad? Decir «yo quiero» presupone «yo puedo querer», es decir, presupone mi libertad. Cuando otros suplantan mi voluntad, es decir, quieren por mí, lo que me hurtan justamente es la libertad. En tal caso son libres los otros, pero no yo. La libertad es, pues, substancia (Substanz) y determinación (Bestimmung) de la voluntad. «Voluntad sin libertad -escribe Hegel- es una palabra vacía, y a su vez la libertad sólo es real como voluntad». ${ }^{20}$ En el $\S 14$ de su Doctrina del Derecho, los deberes y la religión para el curso elemental dictada en el Gimnasio de Nuremberg los años 1810 y posteriores, Hegel escribe:

La libertad de la voluntad es la libertad en general, y todas las otras libertades son meramente modos de aquella. Cuando se dice «libertad de la voluntad», esto no significa que fuera de la voluntad haya una fuerza, una propiedad, una capacidad que también tuviera libertad. Exactamente como cuando se habla de la omnipotencia de Dios, no se entiende con ello que haya otros seres fuera de él que tengan omnipotencia. Hay libertad ciudadana, libertad de prensa, libertad religiosa. Estos modos de libertad son el concepto universal de libertad en tanto que es aplicado a relaciones u objetos particulares. ${ }^{21}$

\section{3-161}

17 P.-J. Labarrière, «Hegel: une Philosophie du droit», en G. Jarczyk \& P.-J. Labarrière, Hegeliana, París: PUF, 1986, p. 222.

18 GPhR § 4: Werke VII, p. 46.

19 Enz. § 486: Werke X, p. 304.

20 GPhR $\S 4$, Zusatz: Werke VII, p. 46.

21 «Die Freiheit des Willens ist die Freiheit im allgemeinen, und alle anderen Freiheiten sind bloss Arten davon. Wenn man sagt «Freiheit des Willens», so ist nicht gemeint, als ob es ausser dem Willen noch eine Kraft, Eigenschaft, Vermögen gäbe, das auch Freiheit hätte. Gerade wie, wenn man von der Allmacht Gottes spricht, man dabei nicht versteht, als ob es dabei noch 
Libertad es, por consiguiente, «libertad de la voluntad». ¿Qué es la voluntad para Hegel? ${ }^{22}$ La respuesta es: Inteligencia (Intelligenz).

El espiritu es ante todo inteligencia y las determinaciones por las que pasa su desarrollo -desde el sentimiento, a través de la representación, hasta el pensamiento-constituyen el camino para producirse como voluntad, la cual, en cuanto espíritu práctico, es la verdad próxima de la inteligencia. ${ }^{23}$

La voluntad, en efecto, sólo es libre, y por lo tanto verdadera voluntad, en cuanto inteligencia pensante. ${ }^{24}$ Por consiguiente, el principio tanto del derecho como de la moralidad y de la eticidad no es el sentimiento (Gefühl), el corazón (Herz) o el entusiasmo (Brust) $)^{25}$ sino el pensamiento. ${ }^{26}$

Ya Spinoza identificó voluntad y entendimiento («voluntas, \& intellectus unum, \& idem sunt» ${ }^{27}$ ) ya que entendía la voluntad no como deseo sino como juicio. Toda idea involucra un juicio (es decir, una afirmación o negación de lo ideado por ella), por lo tanto, toda idea involucra un acto de la voluntad. Toda ideación tiene un carácter performativo, ilocucionario. Conocer es ya querer.

En Hegel la inteligencia es voluntad porque pone su contenido. Por eso el derecho es, como hemos visto, positivo. La idea pone el ideatum y esa posición es práxis.

andere Wesen gäbe ausser ihm, die Allmacht hätten. Es gibt also bürgerliche Freiheit, Pressfreheit, politische, religiöse Freiheit. Diese Arten von Freiheit sind der allgemeine Freiheitsbegriff, insofern er angewandt ist auf besondere Verhältnisse oder Gegenstände»: Werke IV, p. 222.

22 Sobre el concepto de voluntad en Hegel véase B. Quelquejeu, La volonté dans la philosophie de Hegel, París: Seuil, 1972.

23 «Der Geist zunächts Intelligenz und dass die Bestimmungen, durch welche sie in ihrer Entwicklung fortgeht, vom Gefühl durch Vorstellen zum Denken der Weg sind, sich als Wille hervorzubringen, welcher, als der praktische Geist überhaupt, die nächste Wahrheit der Intelligenz ist»: GPhR § 4, Anmerkung: Werke VII, p. 48.

24 «Der Wille nur als denkende Intelligenz wahrhafter, freier Wille ist» (La voluntad sólo es voluntad verdadera, libre como inteligencia pensante) GPhR $§ 21$, Anmerkung: Werke VII, p. 72 .

$25 G P h R$ § 21: Werke VII, p. 72. Velado ataque al sentimentalismo y subjetivismo de Schleiermacher. Véase sobre la crítica de Hegel a Schleiermacher: F. Duque, La Restauración. La escuela hegeliana y sus adversarios, Madrid: Akal, 1999, pp. 37 ss.

26 GPhR § 21, Anmerkung: Werke VII, p. 72: «Dies Selbstbewusstsein [das Selbsbewusstsein des Willens], das durch das Denken sich als Wesen erfasst und damit eben sich von dem Zufälligen und Unwahren abtut, macht das Prinzip des Rechts, der Moralität und aller Sittlichkeit aus» (Esta autoconciencia [la autoconciencia de la voluntad] que se concibe como esencia por el pensamiento y con ello se desprende de lo contingente y no verdadero, constituye el principio del derecho, de la moralidad y de toda eticidad).

27 Eth. II, prop. 49, coroll. 
La inteligencia -leemos en el $§ 468$ de la Enciclopedia-sabiéndose a sí misma como determinante del contenido..., es voluntad. ${ }^{28}$

La voluntad, por ese motivo, es la existencia o realidad del espíritu. ${ }^{29}$ Hegel en esto es heredero de la distinción kantiana entre uso teórico y uso práctico de la razón. Kant, como es sabido, distingue dos tipos de conocimiento en función de su relación con el objeto: si el conocimiento se limita a determinar (bestimmen) su objeto (el cual por ello tiene que estar previamente dado) se trata de un conocimiento teórico (theoretische Erkenntnis); si, por el contrario, el conocimiento lo hace efectivo (wirklich zu macht) estamos ante un conocimiento práctico (praktische Erkenntnis). ${ }^{30}$

Hegel retoma esta distinción en su Propedéutica de Nuremberg:

La conciencia teórica considera lo que es, y lo deja tal como es. La [conciencia] práctica, por el contrario, es la conciencia activa, que no deja lo que es tal como es, sino que produce cambios en ello y genera determinaciones y objetos desde sí misma. ${ }^{31}$

Esta conciencia práctica (praktische Bewusstsein) que crea existencia, realidad, es la voluntad. La voluntad, por consiguiente, es espíritu (es decir, inteligencia) pero práctico. genera, por lo tanto, determinaciones y objetos desde sí misma. Frente a la conciencia teórica que presupone su objeto como algo previo y ajeno a ella, la conciencia práctica supera la extrañeza de su objeto al no ver en éste sino un producto suyo.

Marx se revelará heredero de Kant y Hegel al entender que la relación productiva del trabajador con la mercancía es más verdadera, fundamental y originaria que la relación contemplativa o adquisitiva del burgués, la cual está siempre amenazada por la fetichización del objeto y, por tanto, por la correlativa cosificación del sujeto.

Si la voluntad sólo es libre en cuanto inteligencia pensante, esclavo no será, primo et per se, quien no tiene libertad, sino quien no se piensa. Como escribe Hegel

28 «Die Intelligenz sich wissend als das Bestimmende des Inhalts... ist Wille» GW XX, p. 465 .

29 Véase Enz § 469: GW XX, p. 466.

$30 \mathrm{KrV}$, Vorrede zur zweiten Auflage, B IX-X.

31 «Das theoretische Bewusstsein betrachtet das, was ist, und lässt es, wie es ist. Das praktische hingegen ist das tätige Bewusstsein, welches das, was ist, nicht so lässt, sondern Veränderungen darin hervorbringt und aus sich Bestimmungen und Gegenstände erzeugt»: Rechts-, Pflichten- und Religionslehre für die Unterklase (1810 ss.), Erläuterungen zur Einleitung $\S 4$ : Werke IV, p. 212. 
El esclavo no conoce su esencia, su infinitud, la libertad, él no se sabe como esencia, y por lo tanto no se sabe, es decir, no se piensa. ${ }^{32}$

Ignorar la propia libertad implica no quererla. Para tomar conciencia de la propia esclavitud es preciso antes saberse libre. Sólo quien se sabe tal es capaz de escapar de sus prisiones. Para Hegel saberse libre es ser libre. ${ }^{33}$ No se trata, por lo tanto, de tener el mero sentimiento de libertad, de presumirse libre sino de saberse libre, porque sólo quien se sabe tal hará efectiva esa libertad.

\section{LA DIALÉCTICA DE LA VOLUNTAD}

La voluntad también tiene su Odisea, su viaje hacia sí misma. En ese viaje atraviesa tres momentos descritos en los $\S \S 5$ a 7 de la Introducción a los Fundamentos de la Filosofía del derecho. En el primero de ellos la voluntad aparece como pura indeterminación, en el segundo como determinación y en el tercero como autodeterminación. Tríada análoga a la que abre la Doctrina del ser en la Ciencia de la lógica: ser (Sein), ser-ahí (Dasein) y ser-para-sí (Fürsichsein). El ser (Sein) es lo (inmediato) indeterminado. Por eso equivale a nada (universalidad abstracta). El ser-ahí (Dasein) es «el ser con una determineidad». ${ }^{34}$ Es, por lo tanto, algo que se opone a otro (particularidad). El ser-para-sí (Fürsichsein) es el ser que, en tanto que algo que se opone a otro, deviene lo otro de lo otro. Resulta así que en su pasar a otro viene a retornar a sí. Es, por consiguiente, uno (singularidad). Es un retorno a lo universal: lo uno, lo singular es él mismo una substancia, una totalidad (por eso puede reflejar dialécticamente, monadológicamente, todo: cada ente, cada uno es, como ya escribió Leibniz, un mundus concentratus).

En un primer momento la voluntad se presenta como carente de todo contenido determinado, de toda limitación. ${ }^{35}$ Es el momento de la universalidad (Allgemeinheit) abstracta. ${ }^{36}$ Es el pensamiento puro de sí mismo, «la pura

32 «Der Sklave weiss nicht sein Wesen, seine Unendlichkeit, die Freiheit, er weiss sich nicht als Wesen, - und er weiss sich so nicht, das ist, er denkt sich nicht». GPhR § 21: Werke VII, p. 72.

33 En la nota al § 482 de la Enciclopedia podemos leer: «Wenn das Wissen von der Idee, d.i. von dem Wissen der Menschen, dass ihr Wesen, Zweck und Gegenstand die Freiheit ist, spekulativ ist, so ist diese Idee selbst als solche die Wirklichkeit der Menschen, nicht die sie darum haben, sondern [die] sie sind» (Cuando el saber de la idea, es decir, del saber del hombre, [e.d., saber] que su esencia, fin y objeto es la libertad, es especulativo, entonces esta idea es ella misma en cuanto tal la realidad efectiva de los hombres, no porque la tienen, sino porque son ella): $G W X X$, p. 477.

34 Enz. § 90: GW XX, p. 129.

35 Su indeterminación es sólo aparente; en realidad esa carencia de determinación es su determinación. véase: GPhR. § 6, Anmerkung: Werke VII, p. 52.

36 No confundir con la universalidad concreta con la que Hegel caracteriza a la voluntad 
reflexión del yo en sí mismo». ¿Por qué «pura reflexión»? Como escribe Hegel en el $\S 11$ de su Doctrina del Derecho, los Deberes y la Religión para el Curso Elemental de Nuremberg (1810 y ss.), el espíritu tiene reflexión porque

No está atado a lo inmediato, sino que puede ir más allá de él hacia otra cosa, -por ejemplo, de un acontecimiento a la representación de su consecuencia o a un acontecimiento semejante o también a su causa. Yendo más allá de algo inmediato, el espíritu lo ha alejado de sí. Se ha reflejado en sí mismo. Ha entrado en sí mismo. Ha reconocido lo inmediato como un algo limitado, en tanto que le contrapone otro. ${ }^{37}$

La reflexión que define a esta voluntad consiste, por lo tanto, para Hegel en que no se relaciona con algo diferente sino consigo misma, es decir, que es su propio objeto.

Este puro respecto conmigo mismo es el Yo (...) Es la abstracción completa de todo lo que es finito. El Yo como tal no tiene ningún contenido dado por la naturaleza o inmediato, sino que sólo se tiene a sí mismo como contenido. ${ }^{38}$

A la libertad que se corresponde con esta voluntad la denomina Hegel «libertad del vacío» (Freiheit der Leere). Es puramente negativa: «sólo destruyendo algo tiene el sentimiento de su existencia». ${ }^{39}$ Únicamente a través de la aniquilación llega esta voluntad a la autoconciencia. Se realiza destruyendo porque, aunque crea querer algo constructivo (como por ejemplo la igualdad universal), al querer sólo lo universal, en realidad no quiere nada. Hegel cree descubrir esta libertad «en el fanatismo de la pura contemplación hindú» ${ }^{40}$ y en general en los fanatismos que tanto en el ámbito religioso como político desembocan en la destrucción de todo orden social existente. Esta voluntad

libre en GPhR § 24: Werke VII, p. 75.

37 «Er ist nicht an das Unmittelbare gebunden, sondern vermag darüber zu etwas anderem hinauszugehen, -z. B. von einer Begebenheit zur Vorstellung ihrer Folge oder einer ähnlichen Begebenheit oder auch ihrer Ursache. Indem der Geist auf etwas Unmittelbares hinausgeht, hat er dasselbe von sich entfernt. Er hat sich in sich reflektiert. Er ist in sich gegangen. Er hat das Unmittelbare, insofern er ihm ein Anderes entgegensetzt, als ein Beschränktes erkannt»: Werke IV, p. 219.

38 «Diese reine Beziehung auf mich selbst ist das Ich (...) Es ist die völlige Abstraktion von allem, was endlich ist. Das Ich als solches hat keinen durch die Natur gegebenen oder unmittelbaren Inhalt, sondern hat nur sich selbst zum Inhalt»: Id. § 12: Werke IV, p. 221.

39 «Nur indem er etwas zerstört, hat dieser negative Wille das Gefühl seines Daseins»: GPhR § 5 Anmerkung: Werke VII, p. 50.

40 «[...] im der Fanatismus der indischen reinen Beschauung»: Ibid. 
indeterminada podría decir, como el Calígula de Albert Camus poco antes de morir: «Ma liberté n'est pas la bonne». ${ }^{41}$

En el Zusatz al $\S 5$ de los Fundamenos de la filosofía del derecho se propone como ilustración histórica de esta clase de libertad el período del terror en la Revolución Francesa. ${ }^{42}$ Ya en la Fenomenología del Espíritu, la «libertad absoluta» (absolute Freiheit) era presentada como una figura de la conciencia para la cual «el mundo es simplemente su voluntad» (die Welt ist ihm schlechthin sein Willen) ${ }^{43}$ Tal libertad desembocaba en el terror, donde esa conciencia sólo encontraba la universalidad en el «obrar negativo» (negative Thun). Es decir, era «la furia del desaparecer» (die Furie des Verschwindens). ${ }^{44}$ La única obra y el único acto de esta libertad es -escribía Hegel- «la muerte más fría y más insulsa, sin más significado que el de cortar una cabeza de col o el de beber un sorbo de agua». ${ }^{45}$

El terror jacobino representaba para el Hegel de la Fenomenología, por así decir, la contrafigura de la tragedia de Antígona en la dialéctica entre libertad y naturaleza expuesta en la cuarta parte de la obra (la que lleva por título: Der Geist, el espíritu). ${ }^{46}$ El Espíritu en la Fenomenología desplegaba la efectuación histórica concreta de lo alcanzado formalmente por la razón: la reconciliación del sujeto y el objeto de un modo concreto, es decir, más allá del individuo que impone su singularidad como lo universal (libertad abstracta) y más allá también de un orden universal que no se reconoce en la singularidad (naturaleza abstracta). Precisamente el terror revolucionario y la muerte de Antígona servían a Hegel para ilustrar estos dos modos de falsa reconciliación. La furia destructora jacobina sería así la de una libertad abstracta que no ha experimentado (no es todavía para sí) su constitutiva (en sî) mediación por la naturaleza; es decir, que no se ha reconocido en ella.

En el segundo momento de la dialéctica de la voluntad esta aparece en su determinación. La voluntad aquí ya no es voluntad en general, indeterminada, sino que se orienta o dirige a un contenido, un objeto. No sólo quiere, sino que quiere algo. Para poder querer no basta con que haya voliciones, es necesario que estas lo sean de cosas determinadas. Es así voluntad determinada (bestimmte).

41 Acto IV $^{\circ}$, escena 14, en A. Camus, Oeuvres complètes, Paris: Gallimard, 2006, t. I, p. 388

42 Werke VII, p. 52.

43 Cap. VI, B III: GW IX, p. 317.

44 Ibid., p. 319.

45 «[...] der kälteste, platteste Tod, ohne mehr Bedeutung, als das Durchhauen eines Kohlhaupts oder ein Schluck Wassers»: Ibid., p. 320.

46 Véase: P.-J. Labarrière, La fenomenología del Espíritu de Hegel. Introducción a una lectura, tr. G. Hirata y J.Mª Ripalda, México: FCE, 1985, cap. VI, pp. 117 ss. 
Es el momento de la particularidad (Besonderheit) y de la exterioridad. Es la voluntad extravertida, dirigida a lo que no es ella.

En el tercer momento la voluntad es autodeterminación (Selbstbestimmung). En él se alcanza la unidad de los dos anteriores (la voluntad como indeterminación y la voluntad como determinación). Es el momento de la singularidad (Einzelheit) concreta. Lo real-racional es siempre en Hegel lo singular; pero lo singular entendido no como un mero esto abstracto y casual, sino como esto concreto, es decir, mediado por la totalidad. La voluntad aquí se reconoce a sí misma en la alteridad, en lo que no es ella y la determina. Como se dice en el Zusatz al § 7 de los Fundamentos de la filosofía del derecho, «sólo al considerar al otro como otro se tiene el sentimiento de sí mismo». ${ }^{47}$ La determinación de la voluntad, por lo tanto, ya no es exterior, objetiva, sino subjetiva. Es autodeterminación. Por eso dice Hegel que aquí «el yo se determina en cuanto es la relación de respectividad (Beziehung) de la negatividad consigo misma». ${ }^{48}$ Es decir, se determina reflexivamente.

\section{LA DIFICULTAD DE DECIR: «TE QUIERO»}

Tres mujeres. Tres modos de entender el amor. Tres maneras de matar al amado. Las heroínas de ópera Turandot, Lulú e Isolda podrían ilustrar los tres momentos en la dialéctica hegeliana de la voluntad libre.

La Turandot de Giacomo Puccini encarna el primer tipo de voluntad, aquella que es pura indeterminación. Ella es la virgen. Libre y pura. E inhumana (inhumana por libre y por pura): «cosa umana non sono, sono la figlia del Cielo libera e pura». No quiere entregar su amor a nadie: «Mai nessun m'avrà!». Ese «nessun» da la medida de su propia nada. Obra así en venganza a un extranjero que antaño traicionó a una ancestra suya (la princesa Lou-Ling). Su pureza es su pasión: «Ah, rinace in me l'orgoglio di tanta purità!» Pasión destructora que no tolera alteridad. Ella encarna la libertad del vacío. Es sólo un rostro de la nada donde todo perece: «Turandot non esiste -dice Pang a Calaf-non esiste che il niente nel quale ti annulli!» Si ella accede a casarse con el pretendiente que descifre los tres enigmas es porque piensa que son indescifrables. Quien falle los acertijos pagará con su cabeza al salir la luna (cuando la luna -símbolo de la pureza- se eleva, sus cabezas lascivas han de caer). Sus pretendientes sin embargo encuentran inexorablemente -aunque demasiado tarde- respuesta al enigma Turandot en la espada del verdugo. Ella es, en efecto, la muerte: $\mathrm{Al}$ grito enamorado de Calaf «Turandot», Ping, Pong y Pang responden al unísono: «la morte». La hija del emperador de China se entrega finalmente a un extranjero

47 «Indem man das Andere als Anderes betrachtet, hat man darin erst sein Selbstgefühl»: Werke VII, p. 57.

48 GPhR § 7: Werke VII, p. 54. 
que descifra los enigmas. Aunque se llame Calaf su verdadero nombre es, como dice Turandot al final de la obra, «Amor». Es decir, quien vence a su pureza no es un amante determinado, sino una abstracción. Una nada vence a otra nada.

Lulú, la heroína de la ópera de Alban Berg es la voluntad que se extravía en sus determinaciones. Lulú es la puta absoluta. No tiene interioridad. «Nunca -le dice a Alwa- he querido aparentar en el mundo otra cosa que aquello por lo que me han tomado. Y nadie me ha tomado jamás por otra cosa que por lo que soy». Pero ¿qué es? Ella se entrega a todos, y es esa entrega. Lulú no es sólo Lulú. Sus múltiples nombres revelan su múltiple identidad: Lulú, Nelly, Eva, Mignon... A ella la definen, la determinan los sucesivos deseos de los hombres que encuentra en su camino. A las preguntas que le hace el pintor al final de la primera escena del primer acto («ipuedes decir la verdad?», «icrees en un creador?», «ipuedes jurar por algo?», «ien qué crees?», «ino tienes ningún alma?», «¿has amado alguna vez?») ella responde siempre, en una parodia del Parsifal wagneriano: «Ich weiss es nicht» (no lo sé). Esa ignorancia de sí expresa magníficamente su carencia total de interioridad. Esa carencia es el abismo donde serán destruidos sus sucesivos amantes. Sólo Jack el destripador se libra de la destrucción matándola a ella.

La Isolda wagneriana ilustra el tercer momento de la dialéctica de la voluntad: la voluntad como autodeterminación. Isolda es la amante paradigmática del mundo de la ópera. Representa -podrían ponerse quizás otros ejemplosla relación de reconocimiento absoluto en que consiste el amor. El amado es amado en tanto que otro. La relación amorosa será la de una identificación con ese otro hasta el punto de sustituirlo. El amante, por lo tanto se ama en última instancia a sí mismo en el otro. La alteridad del amado en el caso de Isolda llega al extremo: ese otro es el mismo que antes era odiado, aquel cuya muerte era deseada. En efecto, Tristán, tiempo atrás, había matado a Morold, caballero irlandés prometido de Isolda, en el curso de una expedición que este emprende contra los habitantes de Cornualles para reclamarles impuestos. Tristán recibe en el combate una herida envenenada. Fingiendo llamarse Tantris (su propio nombre invertido) acude a Isolda para ser curado, conocedor de su arte sanador. Ella le reconoce, pero apiadada por su debilidad, y con la espada presta a ejecutarlo, abandona su intento. Años más tarde (este es el punto en que comienza la acción en el drama wagneriano), siendo conducida Isolda en barco por Tristán para ser desposada por Marke, rey de Cornualles, Isolda decide finalmente dar cumplimiento a esa ejecución abandonada tiempo atrás. Ese odio a Tristán, como es sabido se transmutará en un amor no menos intenso (ambivalencia de los sentimientos, llamó Freud a esta exacta inversión de la misma pasión) en virtud de un cambio operado por Brangäne, su fiel (¿?) sirvienta. Ella sustituye el filtro de muerte que debían beber Tristán e Isolda por el de amor. Ignora, al cambiar las pócimas, que no cambia en realidad nada pues ese amor les 
llevará inexorablemente a la muerte. Esa nueva pasión, inversión de la anterior, operará una exacta inversión de los amantes: cada uno vivirá sólo en y por el otro. Será el otro. Recordemos las palabras de Tristán e Isolda al final de la $2^{\mathrm{a}}$ escena del acto $\mathrm{II}^{\circ}$ :

- Tristan: Tristan du, ich Isolde, nicht mehr Tristan!.

- Isolde: Du Isolde, Tristan ich, nicht mehr Isolde!.

Yo no soy yo sino tú. Tú no eres tú sino yo. Cuando te amo me amo a mí a través de ti. Cuando me amas te amas atí a través de mí. Identidad que presupone la diferencia: eso es el amor.

\section{VOLUNTAD LIBRE EN Y PARA SÍ}

Si la voluntad es finalmente autodeterminación el objeto de su querer no puede ser sino ella misma. La voluntad «no se relaciona con nada que no sea ella misma ${ }_{.}^{49}$ Como escribe Bernard Quelquejeu,

El espíritu libre se encuentra ahora efectivamente consigo, bei sich, ya que no se refiere a ninguna otra cosa sino a sí mismo, y deja caer toda relación de dependencia respecto a una alteridad, tras haber efectuado el completo despliegue de sí mismo. Por eso el querer libre e inteligente es universal: en él toda limitación y toda singularidad particular se encuentran «superadas». ¿En qué consiste la limitación de la singularidad y de la particularidad, sino en la diferencia del concepto con su objeto o su contenido, o por decirlo de otro modo, en la diferencia de su ser para sí subjetivo y de su ser en sí, de su singularidad que excluye y que concluye -y de su universalidad misma? Estas son precisamente las diferencias que el autodespliegue del espíritu subjetivo ha abolido. Con la idea del querer libre se encuentra por lo tanto constituida la de lo universal. ${ }^{50}$

En una anotación de Hegel al $\S 10$ de la introducción a los Fundamentos de la filosofía del derecho podemos leer: «Was ist wahrhafter Wille; freier Wille, der sich zum Gegenstande hat» (lo que es la verdadera voluntad; voluntad libre, que se tiene por objeto). ${ }^{51}$ Ese es el concepto de libertad que se alcanzará en dicha introducción: la libertad es una voluntad de libertad.

En el $\S 12$ de la introducción de la Doctrina del Derecho, los Deberes y la Religión para el Curso Elemental dictada en Nuremberg de los años 1810 y ss., se afirmaba que:

49 GPhR § 23: Werke VII, p. 75.

50 B. Quelquejeu, op.cit., pp. 207-208.

51 Werke VII, p. 61. 
Para que la voluntad sea verdadera y absolutamente libre, lo que ella quiere o su contenido no puede ser otra cosa que ella misma. Ella sólo puede querer dentro de sí misma y tenerse a sí misma como objeto. ${ }^{52}$

La objetividad en la voluntad está puesta por la acción (la acción es el pasar de una determinación interior a la exterioridad). ${ }^{53}$ Eso es lo que caracteriza a la voluntad, como hemos visto, en tanto que espíritu o conciencia práctica. Por eso la voluntad libre se tiene a sí misma por objeto, dado que su objetividad está puesta por ella misma. Ella es, en última instancia, su propio objeto, es decir, es, dicho en términos aristotélicos, práxis no póiesis. Si la póiesis es para el Estagirita una acción cuyo fin es distinto de de ella, es decir, una obra, un érgon. La práxis, en cambio, es ella misma su propio fin, su télos. ${ }^{54}$ Es enérgeia es decir su obra, su érgon, es su obrar mismo. La voluntad en Hegel, es práxis justo en este sentido. Ella es su propio télos. Por lo tanto, la voluntad que tiene un objeto distinto de sí misma sólo es libre en sí, lo que equivale a decir que es la voluntad en su concepto. Sólo será para sí cuando se reconozca expresamente a sí misma como único objeto de sí. Voluntad libre en sí y voluntad libre para sí. ¿Qué quiere decir esta oposición: An-sich-sein / für-sich-sein?

En el Zusatz de Eduard Gans al § 10 de la introducción a los Fundamentos de la filosofía del derecho podemos leer:

El niño es hombre en sí, de momento tiene razón en sí, de momento es posibilidad de razón y de libertad y es así sólo libre según el concepto. Lo que es ahora así de momento en sí, no lo es en su realidad efectiva (Wirklichkeit). El hombre, que es en sí racional, debe abrirse paso por la producción de sí mismo, saliendo fuera de sí... para que llegue a ser también racional para sí. ${ }^{55}$

Lo que es en sí es concepto (es racional) pero aún no efectivamente realizado. Es decir aún no es idea. Lo que es para sí, por el contrario, es lo ya real, efectivo. Hegel tradujo partes del De anima aristotélico. En esa traducción virtió dýnamis por Ansichsein y enérgeia por Fürsichsein. ${ }^{56}$ Lo que es en sí es el lado

52 «Damit aber der Wille wahrhaft und absolut frei sei, kann das, was er will, oder sein Inhalt nichts anderes sein als er selbst. Er kann nur in sich selbst wollen und sich zum Gegenstande haben»: Werke IV, p. 207.

53 Véase el $\S 8$ de las Erläuterungen zur Einleitung de la Rechts-, Pflichten- und Religionslehre für die Unterklase (1810 ss.) de Nuremberg: Werke IV, p. 216.

54 EN, VI, 5, 1140 b 6-7.

55 «Das Kind ist an sich Mensch, hat erst an sich Vernunft, ist erst Möglichket der Vernunft und der Freiheit und ist nur so dem Begriff nach frei. Was nun so erst an sich ist, ist nicht in seiner Wirklichkeit. Der Mensch, der an sich vernünftig ist, muss sich durch die Produktion seiner selbst durcharbeiten durch das Hinausgehen aus sich..., dass er es auch für sich werde»: GPhR § 10: Werke VII, pp. 61-62.

56 Véase W. Kern, «Eine Übersetzung Hegel zu de anima III, 4-5», Hegel-Studien I (1961), pp. 49-88; y K. Düsing, Hegel und die Geschichte der Philosophie, Darmstadt, 1983, 
del ser en tanto que «no respectividad a otro» (nicht Beziehung auf Anderes). ${ }^{57}$ Es, por lo tanto, «simple igualdad consigo mismo» (einfache Gleichheit mit sich selbst). ${ }^{58}$ El ser para sí, por el contrario, consiste en «el ser retornado simplemente a sí en el ser otro, y ser consigo» (in dem Anderssein einfach in sich zurückgekehrt und bei sich zu sein). ${ }^{59} \mathrm{El}$ ser en sí es el sujeto que no se sabe tal, la materia, el contenido; el ser para sí es el sujeto autoconsciente, la forma propia, adecuada de tal contenido. ${ }^{60}$

La voluntad no es sólo libre en sí sino para sí (es verdadera idea) porque tiene por contenido, objeto y fin a sí misma.

\section{LIBRE, ES DECIR, AUTODETERMINADO}

Joachim Ritter ha visto en Aristóteles un antecedente de la concepción hegeliana de la libertad como autodeterminación. En el libro primero de la Metafísica se dice, en efecto, que «ánthropos... eleútheros ho autoû hèneka kaì mè állou ón», es decir, hombre libre es aquél que es por sí mismo y no por otro. ${ }^{61} \mathrm{~J}$. Ritter añade: «Freiheit ist danach für Aristoteles das selbstseinkönnen des Menschen, und Hegel nimmt diesen Begriff auf». ${ }^{62}$ «Eleuthería» no designa aquí, sin embargo, tanto la posibilidad de ser uno mismo sino el hecho de no estar referido, por lo que respecta a su sentido y función, sino a sí mismo (los genitivos «autoû»y «állou» pueden ser leídos en el sentido de pertenencia: hombre libre es aquel que es «de sí mismo» y no «de otro»). La frase de Aristóteles se encuentra en el contexto de una argumentación en la que se explica el carácter desinteresado de la filosofía: este saber no se busca, como otros, en función de ninguna posible utilidad sino por sí mismo. Por eso es «la única ciencia libre». Libre es, por lo tanto, aquello cuyo fín no está fuera sino dentro de sí. Aquello que es para sí.

Una genealogía más cercana (y más determinante) de esta concepción de la libertad debe buscarse en Spinoza. Según Spinoza, «se dice libre aquella cosa que existe en virtud únicamente de la necesidad de su naturaleza, y se determina por sí sola a obrar». ${ }^{63}$ «Por lo tanto -leemos en la carta LVIII a G.H. Schuller- yo no pongo la libertad en la libre decisión; sino en la libre necesidad». ${ }^{64} \mathrm{La}$ libertad

pp. 98-132.

57 Phil. Enz., Oberkl. 1808, § 18: Werke IV, p. 13.

58 Log. Mittelkl. 1810/11 § 7: Werke IV, p. 166.

59 Ibid.

60 Véase F. Duque, Hegel. La especulación de la indigencia, Barcelona: Granica, 1990, p. 30 .

61 Met. A, 2, 982 b 25-26.

62 J. Ritter, Hegel und die französische Revolution, Frankfurt am Main: Suhrkamp, 1965, p. 25.

63 Eth. I, def. VII.

64 B. Spinoza, Opera, ed. de C. Gebhardt, Heidelberg: C. Winters, 1972, t. IV, p. 265. 
para Spinoza no es indeterminación, azar, arbitrariedad o gana, sino determinación interna, autodeterminación. ${ }^{65}$ No tiene, por lo tanto, su fundamento en la voluntad entendida como arbitrio sino en la esencia de la cosa. Con razón se ha escrito que Spinoza es el primer pensador moderno que ontologiza la libertad. ${ }^{66}$ Según esta concepción de la libertad, «sólo Dios es causa libre. Pues sólo Dios existe en virtud únicamente de la necesidad de su naturaleza», ${ }^{67}$ con lo que «causa libre» se revela como equivalente a «causa sui». ${ }^{68}$ Libre es, por consiguiente, lo autocausado.

¿Y Hegel? El tener como momento más propio a lo otro de sí y que por ello es , al mismo tiempo, un tenerse a sí mismo como lo otro de sí, es lo que en su sentido más propio y genuino entiende Hegel por libertad. Ser libre consiste en lograr la desaparición de toda relación de dependencia con algo otro. En la voluntad libre es más bien lo otro lo que depende de mí. Esta independencia ${ }^{69}$ alcanzada por la autodeterminación de la voluntad es la libertad. En el Zusatz al $§ 38$ de la Enciclopedia leemos:

La libertad consiste justamente en que yo no tengo frente a mí ningún absolutamente otro, sino que [este] depende de un contenido que soy yo mismo. $^{70}$

65 Véase M. Gueroult, Spinoza I (Dieu), Paris: Aubier-Montaigne, 1968, p.77.

66 G. Albiac, La sinagoga vacía. Un estudio de las fuentes marranas del espinosismo, Madrid: Hyperion, 1982, pp. 335 ss.

67 Eth. I, prop. XVII, corol. II.

68 «Per causam sui intelligo id, cujus essentia involvit existentiam; sive id, cujus natura non potest concipi, nisi existens»: Eth.I, def. I.

69 Aunque Hegel no lo utiliza aquí, podría utilizarse para caracterizar a la voluntad libre el término reflexivo de «Selbständigkeit». Hegel opone la Selbständigkeit a la Beständigkeit. La Beständigkeit es la subsistencia que caracteriza a las determinaciones del ser. Expresa el carácter abstracto de estas. Que algo es subsistente frente a lo otro quiere decir que «su sentido aparece como completo aun sin su otro» (WdL [1832]: GW XXI, pp. 109-110). La relación con lo otro aquí es extrínseca: es Verhältnis. La Selbständigkeit, por el contrario, es la independencia propia de las determinaciones de la reflexión, y consiste en contener en sí a su otro. La relación con lo otro es inmanente, es respecto, Beziehung. En palabras de M. Theunissen: «La genuina independencia lógico-reflexiva reside en que lo uno que se halla frente a «su otro», es así mismo el todo que contiene a lo otro como su momento propio» (M. Theunissen, Sein und Schein. Die kritische Funktion der hegelschen Logik, Frankfurt a. M.: Suhrkamp, 1980, p. 28). Pues bien, la libertad para Hegel es Selbständigkeit y no Beständigkeit: la voluntad que quiere y lo querido son cada uno el reflejo del otro (son momentos de un mismo movimiento de autodeterminación) y no entes que permanezcan estables y fijos uno frente al otro con una relación de exterioridad entre ellos.

70 «Die Freiheit besteht gerade darin, das ich kein absolut Anderes gegen mich habe, sondern abhänge von einem Inhalt, der ich selbst bin»: Enz. § 38: Werke VIII, p. 111. 
Con razón ha caracterizado Ernst Bloch a la libertad hegeliana como lo profundo (Tiefe) del sí mismo, es decir, el hecho de no encontrarse «afectado por lo objetivo como por algo extraño». ${ }^{71}$ Libre es, en efecto, aquél para quien nada es extraño. Y no lo es porque hace suyo su destino, lo quiere. La libertad aquí no se opone a la necesidad, al destino, sino que es su verdad más profunda. ${ }^{72}$ Hegel se alinea, por lo tanto, con los dos grandes pensadores del amor a lo que hay: Spinoza y Nietzsche. Amor Dei y Amor fati.

Libertad no es azar, ausencia de ley. Lo libre en Hegel obedece a una ley. La suya. La ley que funda su propio vivir. Libre es el legislador de sí, el que sigue la ley que él es. La libertad es esa ley. «Ley -como escribe bellamente Jean-Luc Nancy- de lo que se pone ante todo sin ley, cuya ley precisamente consiste en eso». ${ }^{73}$

\section{LA VERDADERA INFINITUD}

La voluntad que es en y para sí es verdaderamente infinita (wahrhaft unendlich). Lo es porque su objeto no es para ella un otro ni un límite, sino que es ella misma. Sólo en él ha retornado a sí. Como escribe Hegel, «su exterioridad objetiva es lo intrínseco mismo». ${ }^{74}$ La voluntad no alcanza nunca el límite porque ella es el límite.

Hegel distingue entre la mala infinitud: la mera negación de lo finito, un sempiterno ir más allá del límite, un remitir reiteradamente a lo otro de sín (su figura geométrica sería una recta indefinidamente prolongada) y la verdadera infinitud: la infinitud dentro de la finitud, del límite. Esta infinitud es el movimiento reflexivo por el que se retorna eternamente a sí desde y por lo otro (su figura geométrica sería el círculo). Así explica este movimiento reflexivo Hegel:

En su relación con otro, algo es ya un otro frente a él... (ambos no tienen sino una sola y la misma determinación, la de ser un otro), resulta entonces que algo en su pasar a otro, sólo viene a coincidir consigo mismo, y este respecto a sí mismo en el pasar y en lo otro es la verdadera infinitud. ${ }^{76}$

71 E. Bloch, Subjekt-Objekt. Erläuterungen zu Hegel, en Werkausgabe, Frankfurt a. M.: Suhrkamp, 1985, t. VIII, p. 501.

72 WdL (1816): GW XII, p. 12 y Enz. § 158. Véase tambien G. Jarczyk, Système et liberté dans la logique de Hegel, Paris: Aubier-Montaigne, 1980, pp. 9-10.

73 J.-L. Nancy, Hegel, la inquietud de lo negativo, tr. J. M. Garrido, Madrid: Arena libros, 2005 , p. 75.

74 GPhR § 22: Werke VII, p. 74.

75 Véase Enz. §§ 93-94: GW XX, pp. 130-131.

76 «Etwas ist im Verhältniss zu einem Anderen, selbst schon ein Anderes gegen dasselbe... -beide haben keine weitere als eine und dieselbe Bestimmung, ein Anderes zu sein,-so geht hiemit Etwas in seinem Uebergehen in Anderes nur mit sich selbst zusammen, und diese Beziehung im 
Como el visitante de la galería de cuadros del grabado de M.C. Escher, que está a la vez fuera y dentro del cuadro que contempla, la relación con lo otro es al mismo tiempo una infinita relación consigo mismo.

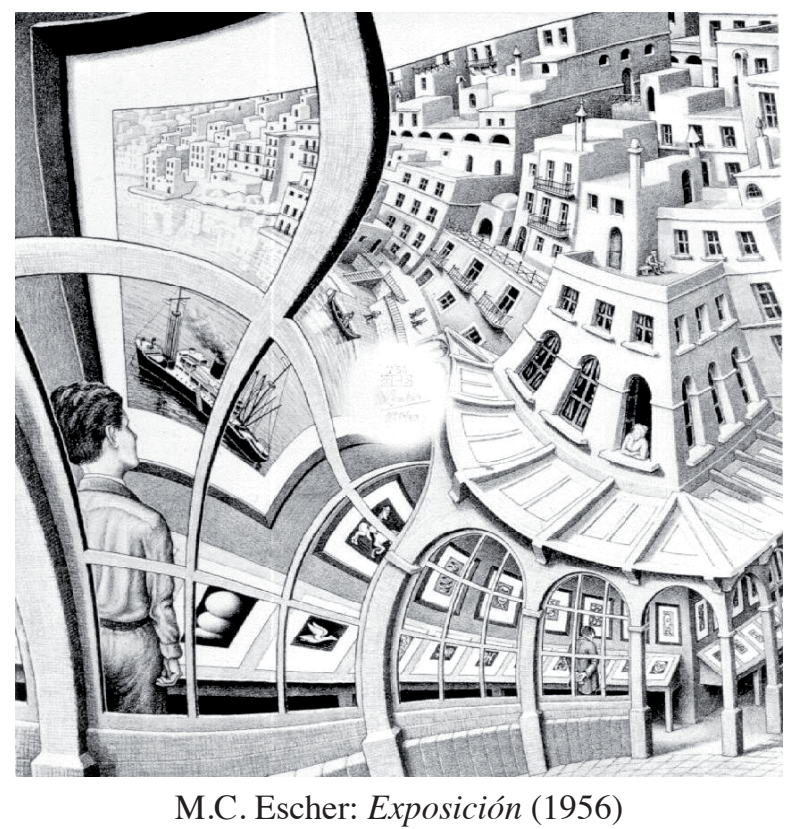

Precisamente esta relación reflexiva con lo otro es la que mantiene la voluntad libre con su objeto.

Recordemos que la libertad en Hegel consiste en no tener en frente ningún absolutamente otro, sino algo cuyo contenido soy yo mismo. ${ }^{77}$ Es decir, la voluntad libre no tiene ningún objeto en el que no reconozca su subjetividad. La voluntad en tanto que libertad es justamente esta dialectización de lo objetivo y lo subjetivo en virtud de la cual el objeto revela un carácter subjetivo (ya que es puesto por el sujeto) y el sujeto se objetiva (en tanto que conciencia o espíritu práctico).

Yo no soy yo sino tú. Tú no eres tú sino yo.

Uebergehen und im Andern auf sich selbst ist die wahrhafte Unendlichkeit»: Enz. § 95: GW XX, p. 131. Sobre el concepto de infinitud en Hegel véase H. Marcuse, Ontología de Hegel y teoría de la historicidad, tr. M. Sacristán, Barcelona: Martínez Roca, , 1970, cap. V, pp. 64-71.

77 Enz. § 38 Zusatz: Werke VIII, p. 111. 
La actividad de la voluntad en tanto que espíritu o conciencia práctica consiste -como hemos visto- en producir, en hacer efectivamente real (wirklich), su objeto. En ese objeto, por ser producto o efectuación del sujeto, éste se reconoce a sí mismo (este reconocimiento lo traducirá Marx así: yo soy el producto de mi trabajo). Por este reconocimiento de sí en lo otro queda superada la contradicción entre sujeto y objeto. ${ }^{78}$ Esta autoproducción del espíritu es el «desarrollo esencial del contenido sustancial de la idea», ${ }^{79}$ es decir, es la idea misma (unidad del concepto de libertad y su realidad).

La voluntad libre, por lo tanto, es aquella que no reconoce en los objetos de su volición sino a sí misma. Sabe que el objeto y fin de su querer no es, no puede ser, sino su propia voluntad libre. Por lo tanto para Hegel libre no sólo es el individuo o pueblo que se cree libre, ni siquiera, aunque pueda parecer paradójico, el que tiene libertad, sino únicamente aquél que quiere su libertad. Ser libre es quererse libre. O dicho con mayor precisión: es libre quien se quiere libre porque se sabe libre. Es decir, quien hace real-efectivo el concepto de su libertad. Recordemos que justamente eso es el Derecho para Hegel: la realización del Concepto de libertad. La libertad no es, por lo tanto, algo que se tiene sino algo que se quiere. Y se quiere porque se ha alcanzado su concepto. Herbert Schnädelbach ha señalado con acierto que la autoreferencialidad de la voluntad en Hegel tiene tanto un sentido cognitivo (el saberse libre de la voluntad libre) como volitivo (el quererse libre de la voluntad libre) ${ }^{80}$

La voluntad libre, como voluntad que se quiere a sí misma como tal voluntad libre tiene un correlato en el hombre revolucionario que se hace ciudadano (y deja por lo tanto de ser súbdito) en el acto mismo en que él declara que lo es. El acto revolucionario de declarar los derechos del hombre revela una voluntad libre entendida como aquella que se quiere a sí misma tal, es decir, libre. ${ }^{81}$ La libertad se pone y presupone a sí misma. libertad.

Si la libertad es sentida como un derecho es porque el derecho es ya la

Los que luchan por la libertad, si saben por lo que luchan, son ya libres. Sólo quiere la libertad quien se sabe libre y sólo se sabe tal quien quiere la libertad.

Herbert Marcuse escribe en Razón y revolución:

78 Véase GPhR § 26: Werke VII, pp. 76-77.

$79 G P h R \S 28:$ Werke VII, p. 79. Véase también (el propio Hegel remite a él) el § 21: Werke VII, pp. 71-72.

80 H. Schnädelbach, Hegels praktische Philosophie, Frankfurt a. M.: Suhrkamp, 2000, p. 187

81 Véase B. Bourgeois, «Hegel et les droits de l'homme», en G. Planty-Bonjour, (dir.), Droit et liberté selon Hegel, Paris: PUF, 1986, pp. 21-22. 
No es cualquier individuo, sino el individuo libre, el que «desea la libertad». La libertad en su forma verdadera sólo puede ser reconocida y deseada por un individuo que sea libre. El hombre no puede conocer la libertad si no la posee; ha de ser libre a fin de volverse libre. La libertad no es simplemente un status que el individuo posee, sino una acción que lleva a cabo como sujeto autoconsciente. ${ }^{82}$

La libertad es el ejercicio mismo de la voluntad. Ya hemos visto que el querer en Hegel es la forma más perfecta de conocer: aquella que crea su objeto. Esa creación es la libertad. Pero esa libertad que constituye en sí toda voluntad ha de serlo para sí para alcanzar genuina plenitud. Ha de hacerse autoconsciente de su genuina y radical libertad. Este es el sentido que tiene la aparentemente paradójica formulación: la voluntad libre es la que quiere la voluntad libre. ${ }^{83} \mathrm{Se}$ trata, por lo tanto, de asumir -más aún, querer - la propia libertad. La libertad que somos. Sin límites, sin condiciones, sin excusas.

Eso es la voluntad libre en Hegel.

Jesús EzquerRa Gómez es doctor en filosofía por la Universidad Autónoma de Madrid con una tesis sobre Hegel y Profesor Ayudante Doctor en la Facultad de Filosofía y Letras de la Universidad de Zaragoza.

Publicaciones recientes:

2006: "Un claro laberinto (el mos geometricus spinoziano)", Estudios filosóficos, vol. LV, no 158 , pp. $67-81$.

2007: "El espejo de Dioniso (acerca del "idealismo" hegeliano)", Youkali. Revista crítica de las artes y el pensamiento, $\mathrm{n}^{\circ} 3$ (El materialismo), pp. 37-46.

2007: "Ulises atado al mástil (el monarca spinoziano)", Isegoría. Revista de filosofía moral y política, $\mathrm{n}^{\circ} 36$ (enero-junio de 2007), pp. 219-238.

2008: "Sade: la escritura, el cuerpo, la libertad", Riff-Raff nº 36 (3 época), pp. 7-13.

Líneas de investigación:

La filosofía hegeliana en general y la lógica de la reflexión en particular, el problema del tiempo en Aristóteles y Hegel, Spinoza, el quietismo de Miguel de Molinos y la filosofía de la naturaleza del Marqués de Sade.

Dirección postal:

Departamentode Filosofía. Facultad de Filosofía y Letras. Ciudad Universitaria. C/ Pedro Cerbuna, $n^{\circ}$ 12. 50009-Zaragoza

Correo electrónico: jesusezq@unizar.es

82 H. Marcuse, Razón y revolución. Hegel y el surgimiento de la teoría social, tr. J. Fombona de Sucre y F. Rubio Llorente, Madrid: Alianza Ed., 1971, p. 187.

$83 G P h R \S 27:$ Werke VII, p. 79. 